\title{
Developmental stability and leadership effectiveness
}

\author{
Carl Senior ${ }^{\mathrm{a}, *}$, Robin Martin ${ }^{\mathrm{b}}$, Geoff Thomas ${ }^{\mathrm{b}}$, Anna Topakas ${ }^{\mathrm{b}}$, \\ Michael West ${ }^{\mathrm{c}}$, Rowena M. Yeats ${ }^{\mathrm{d}}$ \\ a School of Life E' Health Sciences, Aston University, UK \\ b Aston Business School, Aston University, UK \\ c Lancaster University Management School, Lancaster University, UK \\ d College of Medical and Dental Sciences, University of Birmingham, UK
}

\section{A R T I C L E I N F O}

Available online 1 September 2011

\section{Keywords:}

Developmental stability

Fluctuating asymmetry

Leadership effectiveness

Evolutionary psychology

\begin{abstract}
A B S T R A C T
Developmental stability is the degree to which we can withstand environmental or genetic stressors during development. Fluctuating asymmetry (FA), concerns the extent to which the right and left side of the body is asymmetrical and is one way to measure developmental stability. Two studies were carried out that examined both the predictive value of leader FA with leadership behaviors and its role in facilitating group performance. The first study examined the hypothesis that a leader's FA is correlated with scores on the Multifactor Leadership Questionnaire (MLQ). The results revealed individuals with a more asymmetrical morphology scored higher on the transformational, but not transactional, dimensions of leadership behavior. A second study examined the hypothesis that asymmetrical morphology and leadership effectiveness would share a positive relationship. In this study participants who led a business game exercise, revealed a positive relationship between FA and self-reported well-being and task satisfaction. Importantly, there was also a positive correlation between the leader's FA score and group performance. The role that developmental stability may play in leadership effectiveness is discussed in the wider context of evolutionary psychology.
\end{abstract}

(c) 2011 Elsevier Inc. All rights reserved.

\section{Introduction}

Critical to understanding human behavior is an appreciation of how biological factors affect it. This approach is evolutionary psychology in its broadest sense but until recently this field has concentrated mainly on examining behaviors that are closely aligned to evolutionary survival such as; sexual attraction, competition for resources, mate choice etc. (see Wilson, 1978 for a review). However, it is becoming increasingly clear that such a perspective is also a relevant paradigm for the study of behavior that occurs within the work and organizational context. This paper deals with one organizational context, the leadership process; an area of research that is gaining considerable interest among evolutionary psychologists (Nicholson \& White, 2006; Van Vugt, Hogan, \& Kaiser, 2008).

Employing the evolutionary perspective within the leadership context has great utility for three fundamental reasons. First, as the evolutionary approach draws upon a wide range of disciplines such as anthropology and population genetics, it affords the opportunity to engage and draw upon these diverse fields. Second, since it involves the study of traits that are adaptive (i.e. evolutionarily beneficial), the organizational scientist can examine the efficacy of behaviors that occur both within organizations as well as in general society (see e.g., Nicholson, 1998). Finally, following from the last issue, such research can encourage organizational practice to become more parsimonious with behaviors from our evolutionary past which, in turn, may potentially increase its effectiveness (Van Vugt et al., 2008).

The utility of examining adaptive behaviors within organizations can be informed by a model developed by Tinbergen (1963). Tinbergen's model proposes that behaviors can be examined at different levels of analysis. With regard to leadership the current

\footnotetext{
* Corresponding author.

E-mail address: c.senior@aston.ac.uk (C. Senior).
} 
studies are concerned with analysis at both the ontogenetic (i.e., the developmental) and adaptive (i.e., the evolutionary function) levels. The main research approach is to ask what mechanisms emerge in our developmental lifespan, or in our evolutionary past, that would indicate a propensity for leadership effectiveness? In the present paper, one possible mechanism for leadership effectiveness is explored, namely developmental stability. The aim of this research is to examine the causal role between developmental stability and leadership behaviors and effectiveness. These studies explore the link between developmental stability and leadership, and as such contribute to both the evolutionary and leadership literatures.

\subsection{Potential for evolutionary psychology to study leadership}

The psychology of leadership is a vast topic, which has to date received approximately a century of scientific study (Gill, 2006). Even so, while there has been a considerable amount of interest in understanding the psychological factors driving leadership behaviors there has been very little research, if any, exploring the sociobiology that may facilitate leadership effectiveness.

Early trait theories of leadership identified particular characteristics such as intelligence, height, and self confidence as being more related to leaders than to non-leaders (House \& Beatz, 1979; Mann, 1959; Stogdill, 1974). Following a reanalysis of Mann's early findings, which showed intelligence and leadership effectiveness to be moderately correlated, interest in these early trait theories of leadership resurged (Judge, Ilies, \& Colbert, 2004; Lord, De Vader, \& Alliger, 1986). Trait theories of leadership were also supported by the emerging behavioral school of thought where two studies in particular, the University of Michigan and Ohio State University leadership studies, identified two distinct aspects of effective leadership (see Katz, Maccoby, Gurin, \& Floor, 1951). These were 'consideration' and initiating 'structure', and refer to the prosocial empathy of leaders toward the subordinate work group and the methods by which organizational goals are achieved. This early research shows that leadership is not a single unitary concept but an umbrella term encompassing a range of distinct cognitions.

Currently, the most widely accepted approach to understanding leadership behaviors comes from the transformational/transactional approach (Bass, 1985). Transformational leadership refers to behaviors that inspire and challenge others to reach goals (Judge, Bono, Illes, \& Gerhardt, 2002). The transformational leader motivates followers and encourages them to transcend self-interest for the good of the group. These leaders are thus more suited to transforming an organization by supporting a general culture for change. Transformational leaders also tend to use more social-based heuristics in their leadership strategies (Yammarino \& Dubinsky, 1994). Conversely, transactional leaders lean toward observing followers and rewarding desired behaviors accordingly (Arnold et al., 2005). Such a distinction can also be described as task vs. relationship-orientated leadership (Graen \& Uhi-Bien, 1995). Thus, transformational leaders routinely demonstrate the capacity to develop successful leader-follower relationships, which is diagnostic of effective leadership and is also generally more effective than intelligence in predicting leadership effectiveness (Bryant, 2003; Judge et al., 2002, 2004).

Recently there has been interest in understanding whether this form of relationship-orientated leadership can be learnt, or instead whether it has some degree of a biological basis (see e.g., Arvey, Rotundo, Johnson, Zhang, \& McGue, 2006; Arvey, Zhang, Avolio, \& Krueger, 2007; Ilies, Arvey, \& Bouchard, 2006; Johnson, Vernon, Harris, \& Jang, 2004; Johnson et al., 1998). These studies do indeed show that biological factors play an important role in the development of effective leadership behaviors. However, the biological mechanisms that facilitate leadership effectiveness across a range of different situational contexts are still not clear. One possible mechanism is developmental stability. In the next section developmental stability is described prior to a discussion on how it might relate to leadership effectiveness.

\subsection{Developmental stability and fluctuating asymmetry}

Developmental stability is a biological term used to describe the degree to which an organism can resist environmental or genetic stressors (Clarke, 1998). Such stressors (also called developmental noise) can range from poor maternal health when in utero to severe living conditions and, when they do occur, can manifest themselves as small deviations from the development of the normally symmetrical form (Kowner, 2001). From a sociobiological perspective fewer deviations correspond to a greater degree of developmental stability, which in turn reflects a greater degree of genetic fitness (Van Valen, 1962; Waddington, 1957). Here the assumption is that the development of both sides of an organism is governed by the same gene - thus any asymmetrical perturbations caused by injurious occurrences can lead to the inaccurate expression of the healthy, and symmetrical, developmental design (Møller \& Swaddle, 1997; Yeo \& Gangestad, 1998). A useful analogy comes from Prokosch, Yeo, and Miller (2005) who describe developmental stability as "analogous to a builder's ability to turn a blueprint (the genotype) into a well-constructed house (the phenotype)" (p.204).

Measurement of developmental stability is reliably, and traditionally, achieved by calculating fluctuating asymmetry (FA) which is the "left-right asymmetry of a set of typically left-right symmetrical body traits" for example finger lengths or wrist widths etc. (Bates, 2007, p. 41). That is, a greater degree of developmental instability corresponds to less fluctuating symmetry (FS) and greater asymmetry (FA). This measure is considered to be the optimal indirect measure for heritable fitness and has been negatively and positively correlated with a range of different outcomes, e.g., health, mating success, biological fitness and fecundity (Bates, 2007; Furlow, Armijo-Prewitt, Gangestad, \& Thornhill, 1997; Gangestad \& Simpson, 2000; Leung \& Forbes, 1996; Rhodes et al., 2001; Zebrowitz, Hall, Murphy, \& Rhodes, 2002). However, the study of developmental stability is of interest to organizational scientists because recent studies have also shown that morphological symmetry can predict a number of psychological and behavioral traits such as, intelligence and social dominance, traits that have previously been associated with organizational leadership (Heilman \& Stopeck, 1985; Mazur, Mazur, \& Keating, 1984). 
It has already been shown that morphological traits conveying social dominance result in the bearer being more likely to be promoted by the immediate work group within certain situations such as, the military (Mazur \& Mueller, 1996a,b; Mueller \& Mazur, 1996) and there is even evidence identifying dedicated systems in the human brain that are active during the perception of physical traits that evoke the perception of dominance in others (Karafin, Tranel, \& Adolphs, 2004; Oosterhof \& Todorov, 2008). Taking in hand the obvious limitations of neurobiological determinism, this evidence does support the notion that the correct identification of social dominance in others is a necessary social force. However, while dominance hierarchies with a clear 'alpha male' leader may be the norm in non-human primate groups or indeed in certain work situations (such as, the military), they are not normally effective within other organizational contexts (Johnson \& Earle, 2000). The variety of situational factors that may manifest within the contemporary organization ensures that any biological factor could be effective at the organizational, group or even the individual level of the worker. As noted above, cues that advertise social dominance are indeed effective within certain organizational situations; however, within the context of the studies presented in this paper, the effects of FA at the individual and work group level are examined specifically with regard to relationship-based leadership effectiveness. To fully understand the relevance of such relationship-based behaviors a discussion of their possible evolutionary significance is required.

\subsection{Effective leadership and the evolution of prosocial traits}

In the history of human evolution, conflict has been a key catalyst in ensuring the coordination of social groups. Indeed, empirical findings support the notion that human social groups coordinate together naturally during times of stress (Argote, 1982) which would further suggest the presence of an innate mechanism that is both sensitive to such social events and to initiate the need to coordinate together. However, as the early social groups grew in size and complexity it would have become more efficient to defer group decision making to individuals who had skills in a specific area. The ability to coordinate such groups to act would require abilities that go beyond the brutish idiosyncrasies of the dominant alpha male (Boehm, 1993). Again there is support for the presence of dedicated social and cognitive mechanisms that would have evolved to facilitate such skills e.g., theory of mind, social cohesion and even the identification of subordinate potential (Campbell, 1965; Henrich \& Gil-White, 2001; Littlepage, Robinson, \& Reddington, 1997; Povinelli \& Preuss, 1995; Preston \& de Waal, 2002; Van Vugt \& Schaller, 2008). Therefore, as human social groups grew in size and complexity, leaders emerged or were chosen by the subordinates because they possessed prosocial skills that would ensure the group benefited from the outcome of a specific task or problem (Boehm, 1999).

More importantly, it has recently been argued that traits such as integrity, trust and competence, that led to the success of the social group, were adopted by selection processes and now manifest themselves as the traits of effective leaders in contemporary organizations (Epitropaki \& Martin, 2004; King, Johnson, \& Van Vugt, 2009; Nicholson, 2005; Van Vugt et al., 2008; Van Vugt \& De Cremer, 1999). Indeed, the importance of such collegial traits, within certain situations, can be realized by evidence that shows that humans have developed strategies to ensure its successful communication (Small, Shepard-Zeldin, \& Savin-Williams, 1983).

Selection pressures are such that only strategies relevant to our survival are adopted in our developmental history (see e.g., Nicholson, 1998). One such mechanism is the veridical perception of collegial and prosocial traits via developmental cues such as FA (Little \& Jones, 2006). Here both female and male observers assign such traits as 'openness' and 'agreeableness' more to asymmetrical individuals - that is high FA is associated with greater ratings of collegial traits (Fink, Neave, Manning, \& Grammer, 2005). In fact, this ability is so acute that it switches between the luteal and follicular phases of the human menstrual cycle so that females prefer asymmetrical partners during the luteal phase when seeking a partner who is likely to exhibit traits such as trust and integrity etc. and is therefore more likely to engage in a long term secure relationship (Penton-Voak et al., 1999, 2001; PentonVoak \& Perrett, 2000, 2001). In light of the significant physical costs incurred by females during pregnancy, it is clear that correct identification of a potential partner's morphology, as a moderating factor for underlying prosocial traits, is a fundamental imperative (Penton-Voak \& Perrett, 2001).

Given the importance of understanding mechanisms that may contribute to effective leadership in contemporary organizations, it is important to understand how biological factors may drive such a social process. As noted the evolutionary past of humans dictates that we tend to favor collegial individuals as our leaders. These traits are readily attributed to individuals with low developmental stability (i.e., high fluctuating asymmetry). However, to date, the nature of the relationship between FA and leadership effectiveness is not known.

\section{Study 1}

In light of the literature described above, the first study examined the hypothesis that addressed the relationship between developmental stability and self-perceived leadership skills. Collegial and prosocial traits are associated with effective leadership. Asymmetrical individuals are also associated with such traits. Given that transformational leadership is based on the formation of such collegial relationships it is likely that asymmetrical individuals (i.e., high FA) will score high on transformational behaviors. Thus the hypothesis that high FA, i.e., morphological asymmetry, will predict the more collegial transformational leadership will be examined.

\subsection{Method}

\subsubsection{Participants}

Eighty volunteers from a British University ( 69 females: 11 male, mean age $=19$ yrs) were recruited to take part in the study. Before taking part they provided informed consent and were fully debriefed at the end of the testing procedure. 


\subsubsection{Procedure}

All participants were tested individually in a dedicated laboratory. They were first asked to complete the MLQ (5x-leader short form; Avolio \& Bass, 2004) which measures transactional and transformational leadership. Responses to the items in the questionnaire were made on a five-point Likert scale ranging from 'Not at all' (scoring 0 ) to 'Frequently, if not always' (scoring 4 ). Participants were asked to judge how frequently each statement corresponded with their behavior $(a=.74)$.

After the MLQ had been completed, the participants' morphological measurements were taken. A manual caliper was used to measure the right and left sides of seven body features to the nearest $0.05 \mathrm{~mm}$ (i.e., little finger length, ring finger length, middle finger length, index finger length, thumb length, wrist width and ear length; see Fig. 1). For those individuals whose ears were not easily accessible (e.g., due to religious headdress) the measurement was not included in their composite FA score $(n=2)$. Participants were asked whether they had suffered any injury on the measured feature. If this was the case the measurement was also not included in the FA calculations $(n=1)$. In accordance with the accepted practice in studies of FA, each body feature was measured twice and an average summed from these to provide a right $(\mathrm{R})$ and left $(\mathrm{L})$ side measurement. These average measurements were then used to calculate an individual's composite FA score with the formula: $F A=(R-L) /(R+L) * 2$ (adapted from Prokosch et al., 2005).

\subsection{Results}

Prior to an examination of each of the MLQ dimensions with FA scores, an initial comparison of the FA scores across male and female participants failed to reveal significant differences ( $p>0.1$, in all cases) and therefore subsequent analyses are collapsed across this factor.

Table 1 shows the pattern of correlations across all MLQ subscales and FA. Linear regression analyses were conducted with the scores for transformational and transactional leadership traits as dependant variables and the composite FA score as the predictor variable. As was expected, the FA scores failed to predict transactional leadership, $F(1,77)=0.46, p=0.5$. However, a significant regression was revealed for transformational leadership, $F(1,77)=6.45$. $p=0.01$, Adj $\mathrm{R}^{2}=0.06(\beta=0.28, t=2.5, p=0.01)$. More specifically the greater the individual FA score the greater the scores on idealized influence-attributed, $F(1,77)=5.44, p=0.01$, Adj $\mathrm{R}^{2}=0.05(\beta=0.26, t=2.33, p=0.02)$; idealized influence-behavior, $\mathrm{F}(1,77)=3.39, \mathrm{p}=0.04, \operatorname{Adj} \mathrm{R}^{2}=0.03(\beta=0.20, t=1.84$, $p=0.04)$; inspirational motivation, $\mathrm{F}(1,77)=3.37, \mathrm{p}=0.04$, Adj $\mathrm{R}^{2}=0.03(\beta=0.21, t=1.84, p=0.04)$; intellectual stimulation, $\mathrm{F}(1,77)=2.68, \mathrm{p}=0.05$, Adj $\mathrm{R}^{2}=0.02(\beta=0.19, t=1.64, p=0.05)$; individual consideration, $\mathrm{F}(1,77)=3.67, \mathrm{p}=0.03, \mathrm{Adj} \mathrm{R}^{2}=0.03$ $(\beta=0.22, t=1.92, p=0.02)$; contingent reward, $\mathrm{F}(1,77)=4.98, \mathrm{p}=0.01$, Adj $\mathrm{R}^{2}=0.05(\beta=0.25, t=2.23, p=0.01)$ and a negative relationship with management by exception-passive $\mathrm{F}(1,77)=3.72, \mathrm{p}=0.02$, Adj $\mathrm{R}^{2}=0.03(\beta=-0.22, t=-1.93, p=0.02)$, while the scores for management by exception-active failed to reach significance, $F(1,77)=1.35, \mathrm{p}=0.1$.

\subsection{Discussion}

As described above there is a considerable amount of literature indicating that collegial and prosocial traits are regarded as fundamental to leadership effectiveness. Transformational leadership is a conceptualization of leadership behavior that encompasses many of these prosocial traits; furthermore individuals with high FA also exhibit such traits (Zaatari \& Trivers, 2007). The current study was carried out to examine the hypothesis that FA would predict self-reported transformational leadership scores. The results confirmed the hypothesis and revealed that FA measurements did indeed predict the relationship based transformational leadership but not the overall transactional leadership measure.

Although there was not a reliable correlation between FA and the overall transactional measure, there were some reliable associations with some of its sub-dimensions. The scores for contingent reward, revealed a positive relationship with FA. It is believed

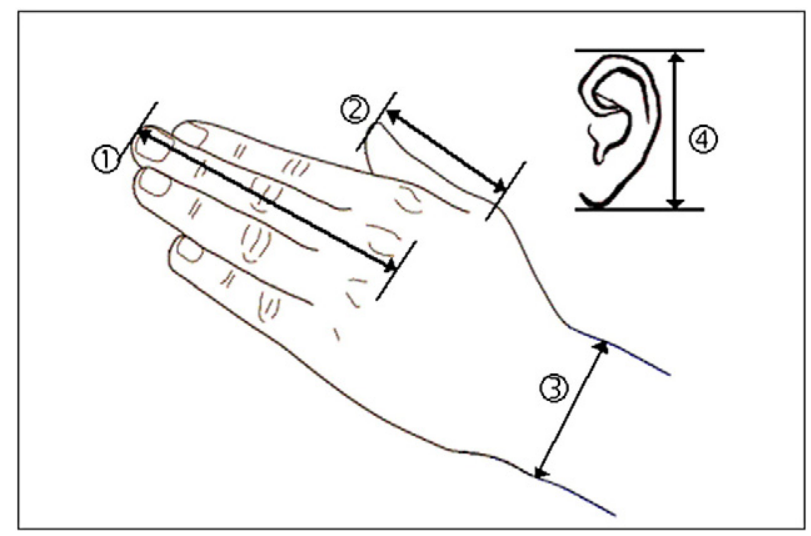

Fig. 1. Diagram of FA measurements taken to calculate the composite FA score in both studies. (1), measurements taken for the index, middle, ring and little fingers. Demonstrated here on the middle finger only. (2) Length of thumb. (3) Width of wrist. (4) Ear length. All measurements were taken in mm using a manual caliper. 
Table 1

Summary statistics and zero order correlations for key variables in study 1. Mean, standard deviation (SD) and composite fluctuating asymmetry scores (FA) are shown with the subscales of the MLQ. Transformational leadership was taken to be the average of the 'Four I's' idealized influence (both attributed and behavior), inspirational motivation, individual consideration and intellectual stimulation. Transactional leadership was taken to be the average of contingent reward and management by exception (both active and passive).

\begin{tabular}{|c|c|c|c|}
\hline Variable & Mean & SD & r \\
\hline Fluctuating asymmetry & 0.13 & .04 & \\
\hline Transformational leadership & 2.48 & .50 & $.28^{* *}$ \\
\hline Idealized influence - Attributed & 2.22 & .60 & $.26^{*}$ \\
\hline Idealized influence - Behavior & 2.45 & .70 & $.20^{*}$ \\
\hline Inspirational motivation & 2.60 & .66 & $.21^{*}$ \\
\hline Individual consideration & 2.67 & .63 & $.22^{*}$ \\
\hline Intellectual stimulation & 2.45 & .62 & $.19^{*}$ \\
\hline Transactional leadership & 1.86 & .41 & .07 \\
\hline Contingent reward & 2.48 & .62 & $.25^{*}$ \\
\hline Management by exception - Active & 1.96 & .70 & .13 \\
\hline Management by exception - Passive & 1.14 & .70 & $-.22^{*}$ \\
\hline
\end{tabular}

** $\mathrm{p}<.001$ one tailed.

$* \mathrm{p}<.05$ one tailed.

that all effective leadership requires the leader to engage in a certain level of behaviors that establish contingent rewards with followers. For this reason, it is not surprising that the result for this dimension was similar to transformational leadership. However, research shows that while contingent reward is important, there is a threshold for the benefits of displaying this behavior and when this is reached, it is the amount of transformational leadership which predicts leadership effectiveness (this is referred to as the 'additive hypothesis' see e.g., Bycio, Hackett, \& Allen, 1995). Finally, it is interesting to note that there was a reliable negative association between FA and management by exception-passive, a set of behaviors that are ineffective for relationship-based leadership (Bass, 1985). Again, this is in line with our hypothesis. People high in FA not only reported high levels of transformational behaviors but also a low level of a style of behavior detrimental to leadership.

While the results of this study supported our hypothesis, a potential limitation concerns the generalizability of self-reported leadership perceptions to leadership effectiveness. Given that most investigators would now regard the quality of the relationship between the leader and the follower to be indicative of leadership effectiveness, further examination of the predicative value of leadership morphology is needed in situ. That is, to examine the effect of morphology on how leader behavior actually contributes to group work output. To achieve this, more ecologically valid data needs to be examined from independent sources as well as those of the leaders' themselves. This was addressed in the second study, which examined the effects of FA on the leaders' wellbeing as well as measures of leadership effectiveness (including observer-ratings and objective measures).

\section{Study 2}

The first study supported the hypothesis that FA is positively correlated with transformational leadership. That is, transformational leaders have more of an asymmetrical morphology. However, this was based on self-reported measures from the leaders themselves and as such is limited in capturing leadership effectiveness. The second study examined the role of FA in facilitating group work outcomes.

The second study was carried out to examine whether FA scores predict a range of work reactions and in particular, team effectiveness, which is often considered to be the preferred way to measure leadership effectiveness (Kaiser, Hogan, \& Craig, 2008). This will take the form of two different levels of analysis. First, at the leader level it is hypothesized that FA will have a positive relationship with measures of work related well-being and task satisfaction. Secondly, that the FA of the leader will positively predict the overall performance of the leader's work group.

\subsection{Method}

\subsubsection{Participants}

The sample consisted of 42 undergraduate students enrolled on business degrees at a British University (15 female: 27 male, mean age $=20$ years). As was the case with the first study, all participants provided informed consent prior to taking part. All participants were informed that they would receive no incentives for participation, including course credit.

\subsubsection{Procedure}

As part of their degree studies, students engage in a business simulation exercise over a period of approximately 22 weeks within one academic year. This ‘Business Game' exercise is designed to be as realistic as possible to a real world business venture. The students are placed into teams of four or five individuals with the aim to manufacture and market an automobile using a PC-based simulation program in a virtual international market. The main activities include presenting a business plan to a committee of practitioners, providing business reports on company performance and making key decisions on manufacturing and marketing the car. Each team has a number of key decisions to make which they can change on a regular basis to meet their business strategy and to respond to 
market conditions. The teams are in competition with each other with team performance affecting the share price of the simulated company. The teams' progress is assessed via a range of individual and team-based assessments (including financial data derived from the computer simulation, e.g., company share price) and forms a core part of their degree assessment.

Each person in the team has a specific role (managing director, financial director, marketing director, etc.). Occasionally, two people might share the same role and some roles might be combined (such as, operations and human resources director). However, the position of managing director is always held by one person and this role is defined as being the leader of the team and has major responsibility for the organization of team activities and decision making. The teams meet every week as part of a tutorial program where they get advice on the task, become familiarized with the computer software, and make class presentations on various aspects of their work. Teams are encouraged to meet outside the formal tutorial program and indeed need to do so in order to complete the various group assignments.

Three measures were taken from the group leaders. First, a fluctuating asymmetry (FA) score was computed using exactly the same procedure as Study 1. Second, work-related well-being was measured using Warr's (1990) combined job-related anxiety-comfort and depression-enthusiasm scales. Participants rated the extent to which they experienced a range of reactions toward their group activity. They completed six positive (e.g., 'optimistic', 'motivated') and six negative (e.g., 'worried', 'anxious') reactions on a 6-point scale which is anchored 1 , 'Never' to 6, 'All the time'. The negative items were then recoded so that higher scores represent lower levels of negative reactions. The positive and negative items were combined to form an overall work-related well-being scale $(a=.901)$. Third, task satisfaction was measured with the following two items; 'All things considered, how satisfying do you find this activity (Business Game)?' and 'In general, to what extent do you enjoy performing this activity (Business Game)?' on 5-point scales which were anchored 1, 'Very Dissatisfied' to 5, 'Very Satisfied'. High scores reflect greater task satisfaction (intercorrelation $r=.498$, $p=.001)$. Scores for each of the items were summed to provide an overall task satisfaction score. In addition, an independent tutorrated performance measure was taken which was provided by a class tutor rating the team's overall performance on a scale developed by Viswesvaran, Schmidt, and Ones (2005). This scale consists of 11 aspects of performance, e.g., 'Quality of work they do', 'Their ability to do the work', 'Their ability to work well together' etc. ( $a=.967)$. The 5-point response scale ranged from 1, 'Poor', to 5, 'Excellent'. The tutor was independent of the study and was also blind to any indication of the leaders' composite FA scores. Finally, a team performance measure was taken. This was the overall team assignment score which the team received at the end of the course. This is a composite score based on two elements; 60\% comes from a group report (1500 word report that addresses the company's performance in the virtual market, that was assessed anonymously by an independent marker).

\subsection{Results}

Table 2 shows the summary statistics and zero order correlations for all variables in this study. As was the case with the first study the gender of the participants did not reveal a significant effect so subsequent analyses were collapsed across gender. As predicted, FA was positively correlated with the leaders' well-being, task satisfaction, the independent tutor rated judgment of group performance as well as the overall team assignment score. More specifically, the greater the leader's FA score the greater was the leader's reported well-being, $F(1,40)=4.15, p=0.04$, Adj $\mathrm{R}^{2}=0.07(\beta=0.31, t=2.03, p=0.4)$; leader's task satisfaction, $F(1,40)=4.79, p=0.03$, Adj $\mathrm{R}^{2}=0.08(\beta=0.32, t=2.19, p=0.3)$; tutor-rated team performance $F(1,40)=4.09 . p=0.04, \operatorname{Adj} \mathrm{R}^{2}=0.07(\beta=0.30, t=2.02$, $p=0.4)$, and team assignment score, $F(1,40)=6.96 . p=0.01$, $\operatorname{Adj~}^{2}=0.12(\beta=0.38, t=2.64, p=0.1)$.

\subsection{Discussion}

The second study was carried out to investigate the relationship between FA scores and a range of outcomes that relate to leadership effectiveness. These outcomes concern the well-being of the leader when engaging with subordinates in a task as well as the subsequent quality of the group's output. As hypothesized there was a positive correlation between the FA scores of the leader and the leaders' well-being. Furthermore, there was a positive correlation with leaders' morphology and independent judgments of the quality of group performance. In other words, those groups with asymetrical leaders were judged to have better levels of performance compared to those groups led by symmetrical leaders. In both cases the results supported the experimental hypotheses.

Table 2

Summary statistics and zero order correlations for all variables in Study 2. Mean, standard deviation (SD) and composite fluctuating asymmetry scores (FA) are shown along with the scores for work well-being and task satisfaction, independent rater judgments for quality of group performance and the final team assignment score (which is an independent measure of the quality of the group work).

\begin{tabular}{|c|c|c|c|c|c|c|c|}
\hline Variable & Mean & SD & FA & Gender & Work-related well-being & Task satisfaction & Tutor-rated performance \\
\hline Fluctuating asymmetry & 0.13 & 0.03 & & & & & \\
\hline Gender & 0.36 & 0.48 & -.07 & & & & \\
\hline Work-related well-being & 4.15 & 0.76 & $.31^{*}$ & .05 & & & \\
\hline Task satisfaction & 3.90 & 0.63 & $.33^{*}$ & .11 & $.33^{*}$ & & \\
\hline Tutor-rated performance & 3.45 & 0.86 & $.30^{*}$ & -.11 & .13 & -.09 & \\
\hline Team assignment score & 67.21 & 7.47 & $.39^{* *}$ & .03 & .06 & .01 & .26 \\
\hline
\end{tabular}

$\mathrm{N}=42$; Gender coded 0 Males, 1 Female.

* $\mathrm{p}<.05$, two tailed.

** $\mathrm{p}<.01$, two tailed. 
Perhaps the most interesting finding was that FA was also related to the overall quality of work that was produced by each group. This is important because it shows that leaders who were high in FA led groups that were more effective in their task. As noted above this was not only a scale measure of tutor-rated performance, but an additional measure of actual performance on the task that combined the computer-simulated financial performance and the group's grade on a written report. Thus it is likely that this was a robust and reliable measure of group performance. The pattern of results suggests that the morphology of the leader is associated with group effectiveness. Taken together, the findings of the second study support the findings of the first study as they suggest that leaders' FA predicts positive leadership behaviors and leadership effectiveness.

\section{General discussion}

The two studies were conducted to examine the previously unexplored relationship between body morphology and leadership effectiveness. These studies were guided by an evolutionary psychology framework that strongly suggests that body asymmetry predicts effective leadership behaviors. The first study showed that greater morphological asymmetry predicts transformational leadership ratings, which is considered to be an index of leadership effectiveness in more relationship-based situations. This was investigated further with the second study where it was found that asymmetrical leaders reported greater well-being and task satisfaction. Additionally, the groups that were directed by these asymmetrical leaders were judged, by independent raters who were blind to the hypotheses of this study, as having an overall better quality of group performance and, more importantly, produced a higher quality output. As such, our research contributes to the leadership literature by being the first to link developmental instability to leadership effectiveness. Within certain organizational settings a sociobiological imperative of 'asymmetry signaling strength' may be more prevalent than previously considered.

\subsection{Leadership effectiveness and asymmetrical body morphology}

The analysis of the various MLQ subscales in the first study revealed reliable correlations in all the transformational subscales with FA scores. All the associations were in the direction toward asymmetrical individuals. For these items significant differences were revealed for idealized influence (attributed), which relates to leader behaviors that are of high moral or ethical conduct and cause the leader to be held in high regard by the followers. Inspirational motivation, individual consideration and idealized influence (Behavior), which are all considered to be transformational traits, also revealed a positive relationship with FA. All of these traits refer to behaviors that are sometimes grouped together under the label 'charismatic leadership' and are considered to be behaviors that lead to positive (and effective) coping styles in social contexts which in turn allows individuals to cope with a changing range of different situations (Bass, 1998; Gomez, Holmberg, Bounds, Fullerton, \& Gomez, 1999). Clearly it would be of benefit to successful leaders to be able to adapt and cope with the constantly changing demands of the immediate working group. Indeed, transformational leaders are often considered to be so effective in this manner that they are sometimes referred to as "change agents' in various organizations (Nemanich \& Keller, 2007).

The traits of inspirational motivation, individual consideration, and idealized influence refer to behaviors that recognize the specific needs of the followers and allow the leader to appropriately develop the relationship with specific individuals. Leaders who score highly on these traits are not merely demonstrating high emotional intelligence (EI), as this would manifest itself as leadership driven purely by a 'gut response' (Palmer et al., 2001). Here it is clear that EI, as a singular construct, is not sufficient to account for the complexity and range of social behaviors for effective leadership (see e.g., Turner, Barling, Epitropaki, Butcher, \& Milner, 2002). Indeed advocates of such approaches are now moving more toward the earlier model of social intelligence to account for the complexities inherent in modern day organizations (Golman \& Boyatis, 2008; Weis, 2008). Such social skills are also seen in human ethological studies where asymmetrical individuals are seen to be more approachable, friendly and also show more prosocial and altruistic behaviors (Zaatari \& Trivers, 2007). Given that such behaviors are also part of the repertoire of emotional competence that is regarded as being part of our evolved leadership preferences, it is intriguing to consider further the possible links between leadership effectiveness in the modern day organization and morphological measurements of asymmetry. It is also worth highlighting that not all of the leadership traits revealed scores that were predicted by the asymmetrical individuals. This shows that calculation of the individual's FA score has utility in differentiating between specific leadership behaviors.

The second study examined the effects of leaders' morphology at both the level of the individual leader as well as the work group. In addition to the well-being of the leader during the process of interacting with subordinates, FA was also related to the overall quality of the group performance as judged by independent raters. Additionally, the second study also revealed a reliable relationship between leaders' morphology and output from the work group. Here, the quality of the work output was greater for those groups led by asymmetrical leaders.

As noted above, asymmetrical individuals tend to advertise a more prosocial and approachable manner compared to their symmetrical counterparts. Within an organizational context this communal style of leadership is regarded as being predominantly a female style of leadership (Eagly, Karau, \& Makhijani, 1995; Eagly, Wood, \& Diekman, 2000). Such leadership has also been termed 'interactive leadership' and tends to involve the leader ensuring that all interactions with subordinates are positive (Rosener, 1990). In light of the fact that in both studies reported here no differences between the genders were revealed, the findings suggest that interactive leadership is not the exclusive domain of female leaders and may be facilitated by a biological precursor.

It is worth stressing again that the raters were blind to the study's hypotheses and had no way of knowing the type of morphology the leaders possessed (as can be seen from the results which are in terms of millimeters and thus impossible to distinguish without careful measurement). The raters judged the performance of the group as a whole and not just the leader. In light of the fact that the 
raters did not have access to the FA measures, these findings show that the more prosocial interactive leadership style of the asymmetrical individuals was clearly effective in facilitating group performance. Such an effect could not therefore have been an artifact of the well-noted relationship between symmetrical morphology and attraction (Senior, 2003), as any such bias that the observer felt toward the physical appearance of the leader would have resulted in positive judgments in the opposite direction than that revealed, i.e., a negative relationship with FA and group performance.

\subsection{Implications of current studies}

The results revealed from both of the studies clearly support the notion that FA has a contributing role in the development of leadership effectiveness. This is contrary to the traditional 'symmetry signals health' hypothesis (Buss, 1994; Noor \& Evans, 2003). At first it would seem logical that a leader, someone at the highest echelons of a social group, should display a high degree of morphological symmetry, which in turn would reflect developmental health. This is highlighted by the fact that some studies have reported that FA is negatively correlated with social dominance. That is, the more asymmetrical a person is, the less socially dominant that person is likely to be (Gangestad \& Thornhill, 1997). However, it must be borne in mind that previous studies have mostly examined social dominance during intrasexual competition, which is a considerably different context from task-based organizational groups. As noted above, the promotion to positions of leadership in the contemporary work place is not based on dominance strategies but is largely a product of democratic processes (Van Vugt et al., 2008).

From an evolutionary perspective the moderating effects of developmental instability (i.e., high FA) can be considered an ontogenic driver of the propensity for leadership effectiveness. The manifestation of FA occurs throughout the entire developmental period and carries with it a considerable social cost. The more asymmetrical an individual is, the less this person is regarded as being intelligent, attractive etc. It is likely that with such an outlook, individuals who have a more asymmetrical morphology may develop social skills to help compensate for their perceived shortcomings - social skills that would be favored in certain situations in the contemporary work place. On the other hand, work contexts that favor characteristics associated with symmetrical morphology (e.g., attractiveness) would benefit from people who are high in development stability (e.g., acting, modeling). Thus, we would expect the work context to moderate the relationship between leaders' developmental stability and leadership effectiveness.

The results of the present studies bridge the link between morphological asymmetry and leadership effectiveness. Research shows that effective leaders manage and monitor social relationships between themselves and subordinates more frequently (Palmer, Walls, Burgis, \& Stough, 2001). Take for example this excerpt from a focus group of leaders who describe: “I don't want to lose my objectivity, even when I'm having emotional reactions... I worry that I'll overcompensate and give them too much influence on my decisions - not because they [the team] intimidate me or anything like that but because I don't want to let my anger get the best of me" (Kaner, 2006, p. 16). This quote clearly demonstrates a heightened awareness of the nature of social relationships but also how such awareness drives the outcomes of leadership decisions. It seems that such insight is experienced more by effective leaders, who also tend to be, as found by the studies reported above, more asymmetrical. However bearing in mind that FA has mostly been examined with outcomes of more direct biological and evolutionary significance, such as fecundity (Mazur, Halpern, \& Udry, 1994), it is useful to embed the findings from both studies in the context of other leadership research, specifically research that has considered the heritability of leadership.

The 'nature/nurture' debate frames leadership in a pre-determined light, e.g., "our experience has led us to believe that much of leadership talent is hardwired in people before they reach their early or mid-twenties" (Sorcher \& Brant, 2002, p. 81) while others have shown that leadership skills can be improved with training (Barling, Weber, \& Kelloway, 1996). Clearly there is no one-toone relationship between a given factor and leadership abilities with research indicating that heritable aspects can account for around $30-60 \%$ of the variance contributing to such abilities (Arvey et al., 2006).

Given that asymmetrical people are generally considered to be less intelligent as well as less dominant (and less attractive) than their symmetrical counterparts, it is likely that such negative social traits will not engender much social support, and thus asymmetrical individuals may have developed adaptive strategies by which to compensate for these perceived social failings. Thus developmental instability may have driven the asymmetrical individual to affiliate more with the immediate social group and in doing so ensured that they evolved compensatory behaviors, which are translated into the relationship-focused transformational leadership strategies that are effective within some organizational settings.

\subsection{Conclusion and future directions}

The emerging use of evolutionary psychology within the organizational sciences, to compliment literature in the natural sciences, is important as it allows models of organizational behavior to be examined within a framework that follows human evolution and is therefore "consistent with human nature" (Nicholson \& White, 2006, p. 118). As developmental stability manifests itself morphologically, the current findings thus demonstrate a clear morphological association between leadership effectiveness and the facilitation of high quality work output in certain situations.

Taking in hand the fact that both studies reported here utilized undergraduate students as participants it is worth noting that as leadership behavior is embedded within organizations, these studies contribute in part to closing the gap between research and practice in this field (Gordon \& Howell, 1959). This is diagnostic of the Organizational Cognitive Neuroscience approach and indeed the studies reported here should be considered to come from this perspective (Senior et al., 2011). As noted above, prosocial and collegial traits are an important aspect of leadership effectiveness for a number of reasons. Leaders can shape the 
mood state in those who they work alongside to result in a wide variety of organizational outcomes such as improved team output (George, 1995). Taken together this research adds to the considerable body of literature that highlights the importance of such social insight within leaders to place the group in its optimal position for success (Barsade \& Gibson, 2007).

As highlighted throughout the discussion, the nature of the task and contextual factors play an important role in determining leader characteristics and behaviors that facilitate positive leadership outcomes (for an overview see e.g., Liden \& Antonakis, 2009). What might be effective in certain situations might have the opposite or no effect in others. Study 1 unveiled a link between FA and transformational behaviors in leaders irrespective of context, under the assumption that in many contemporary organizations transformational behaviors produce the desired leadership outcomes. Building on this, Study 2 findings demonstrated that in situations of group-based work on intellectually challenging tasks FA is again associated with better leadership outcomes, both in terms of the leaders' psychological reactions as well as group performance. Therefore, both studies focused on leadership under conditions where interpersonal relationships are of key importance, and should be interpreted in this light.

However, in different contexts transformational or prosocial behaviors, that are associated with high FA, might not be ideal in facilitating high performance. For instance, at the organizational level Pawar and Eastman (1997) propose that transformational leadership will have a more positive effect in organizations focusing on adaptation rather than efficiency, boundary spanning rather than technical functions, having a simple or adhocracy structure rather than machine bureaucracy, professional bureaucracy or divisional structure, and having a clan rather than market or bureaucratic mode of governance. Additionally, it has been argued that effective leadership characteristics and behaviors can vary at the individual level as well, depending on both contextual factors as well as followers' prototypes and cognitive schemas (Lord, Brown, Harvey, \& Hall, 2001). In light of this it is important to acknowledge that the findings reported here refer to a specific set of leadership behaviors and contextual boundary conditions. Future research focusing on the contextual and follower-specific factors that affect the relationship between FA and leadership effectiveness would complement our findings and shed light on the conditions under which developmental stability and instability are linked to beneficial leadership characteristics and behaviors.

Overall these studies have demonstrated the value of using the evolutionary perspective for research into the organizational sciences, however, it is worth bearing in mind the complexities of effective leadership. While these studies, for the first time, show the relationship between developmental stability and leadership effectiveness, we recognize that this can account for only part of the leadership process. Further study of the relationship that FA has with other organizational situations would clearly be informative.

\section{Acknowledgments}

We would like to thank the two anonymous reviewers who provided helpful and constructive comments on earlier drafts of this paper.

\section{References}

Argote, L. (1982). Input, uncertainty and organisational coordination in hospital emergency units. Administrative Science Quarterly, 27, 420-434.

Arnold, J., Silvester, J., Patterson, F., Roberston, I., Cooper, C., \& Burnes, B. (2005). Work psychology: Understanding human behavior in the workplace. Harlow: Prentice Hall.

Arvey, R. D., Rotundo, M., Johnson, W., Zhang, Z., \& McGue, M. (2006). The determinants of leadership role occupancy: Genetic and personality factors. The Leadership Quarterly, 17, 1-20.

Arvey, R. D., Zhang, Z., Avolio, B. J., \& Krueger, R. F. (2007). Developmental and genetic determinants of leadership role occupancy among women. Journal of Applied Psychology, 92, 693-706.

Avolio, B. J., \& Bass, B. M. (2004). Multifactor leadership questionnaire (Third edition and sampler set). California: Mind Garden.

Barling, J., Weber, T., \& Kelloway, E. K. (1996). Effects of transformational leadership training on attitudinal and financial outcomes: A field experiment. Journal of Applied Psychology, 81, 827-832.

Barsade, S. G., \& Gibson, D. E. (2007). Why does affect matter in organizations? Academy of Management Perspectives, 21, 36-59.

Bass, B. M. (1985). Leadership and performance beyond expectations. New York: Free Press.

Bass, B. M. (1998). Transformational leadership, industrial, military and educational impact. Mahwah, NJ: Erlbaum.

Bates, T. C. (2007). Fluctuating asymmetry and intelligence. Intelligence, 35, 41-46.

Boehm, C. (1993). Egalitarian society and reverse dominance hierarchy. Current Anthropology, 34, 227-254

Boehm, C. (1999). Hierarchy in the forest. London: Harvard University Press.

Bryant, S. E. (2003). The role of transformational and transactional leadership in creating, sharing and exploiting organizational knowledge. Journal of Leadership and Organizational Studies, 9, 32-44.

Buss, D. M. (1994). The evolution of desire: Strategies of human mating. New York: Basic books.

Bycio, P., Hackett, R. D., \& Allen, J. S. (1995). Further assessments of Bass's (1985) conceptualisation of Transactional and Transformative leadership. Journal of Applied Psychology, 80, 468-478.

Campbell, D. T. (1965). Ethnocentric and other altruistic motives. In R. Levine (Ed.), Nebraska symposium on motivation, Vol. 13. (pp. 283-311)Lincoln: University of Nebraska Press.

Clarke, G. M. (1998). The genetic basis of developmental stability Individual and population asymmetry parameters. Heredity, 80, 553-561.

Eagly, A. H., Karau, S. J., \& Makhijani, M. G. (1995). Gender and the effectiveness of leaders: A meta-analysis. Psychological Bulletin, 117, 125-145.

Eagly, A. H., Wood, W., \& Diekman, A. B. (2000). Social role theory of sex differences and similarities: A current appraisal. In T. Eckes, \& H. M. Traitner (Eds.), The developmental social psychology of gender. Mahwah, NJ: Erlbaum.

Epitropaki, O., \& Martin, R. (2004). Implicit leadership theories in applied settings: Factor structure, generalizability and stability over time. Journal of Applied Psychology, 89, 293-310.

Fink, B., Neave, N., Manning, J. T., \& Grammer, K. (2005). Facial symmetry and the 'big-five' personality factors. Personality and Individual Differences, 39, 523-529.

Furlow, F. B., Armijo-Prewitt, T., Gangestad, S. W., \& Thornhill, R. (1997). Fluctuating asymmetry and psychometric intelligence. Proceedings of the Royal Society of London, 264, 823-829.

Gangestad, S. W., \& Simpson, J. (2000). The evolution of human mating: trade-offs and strategic pluralism. Behavioral \& Brain Sciences, 23, 573-644.

Gangestad, S. W., \& Thornhill, R. (1997). Human sexual selection and developmental stability. In J. A. Simpson, \& D. T. Kenrick (Eds.), Evolutionary personality and social psychology. New Jersey: Erlbaum. 
George, J. M. (1995). Leader positive mood and group performance: the case of customer service. Journal of Applied Social Psychology, 75, $698-709$.

Gill, R. (2006). Theory and practice of leadership. London: Sage.

Golman, D., \& Boyatis, R. (2008). Social intelligence and the biology of leadership. Harvard Business Review, 86, 74-81.

Gomez, R., Holmberg, K., Bounds, J., Fullerton, C., \& Gomez, A. (1999). Neuroticism and extraversion as predictors of coping styles during early adolescence. Personality and Individual Differences, 27, 3-17.

Gordon, R. A., \& Howell, J. E. (1959). Higher education for business. New York: Columbia Press.

Graen, G. B., \& Uhi-Bien, M. (1995). Relationship-based approach to leadership: developing of leader-member exchange (LMX) theory over 25 years: Applying a multi-level domain theory. The Leadership Quarterly, 6, 219-247.

Heilman, M. E., \& Stopeck, M. H. (1985). Attractiveness and corporate success: Different causal attributions for males and females. Journal of Applied Psychology, 70, 379-388.

Henrich, J., \& Gil-White, F. (2001). The evolution of prestige: Freely conferred deference as a mechanism for enhancing the benefits of cultural transmission. Evolution and Human Behavior, 22, 165-196.

House, R. J., \& Beatz, M. L. (1979). Leadership: Some empirical generalizations and new research directions. In B. M. Staw (Ed.), Research in organizational behavior. Connecticut: JAI Press.

Ilies, R., Arvey, R. D., \& Bouchard, T. J. (2006). Darwinism behavioral genetics and organizational behavior: A review and agenda for future research. Journal of Organizational Behavior, 27, 121-141.

Johnson, A. W., \& Earle, T. (2000). The evolution of human societies. Stanford, CA: Stanford University Press, USA.

Johnson, A. M., Vernon, P. A., Harris, J. A., \& Jang, K. L. (2004). A behavioral investigation of the relationship between leadership and personality. Twin Research, 7, $27-32$.

Johnson, A. M., Vernon, P. A., McCarthy, J. M., Molson, M., Harris, J. A., \& Jang, K. J. (1998). Nature vs nurture: Are leaders born or made? A behavior genetic investigation of leadership style. Twin Research, 1, 216-223.

Judge, T. A., Bono, J., Illes, R., \& Gerhardt, M. (2002). Personality and leadership: A qualitative and quantitative review. Journal of Applied Psychology, 87, 765-780.

Judge, T. A., Ilies, R., \& Colbert, A. E. (2004). Intelligence and leadership: A quantitative review and test of theoretical propositions. Journal of Applied Psychology, 89, $542-552$.

Kaiser, R. B., Hogan, R., \& Craig, S. B. (2008). Leadership and the fate of organizations. American Psychologist, 63, 96-110.

Kaner, S. (2006). Five transformational leaders discuss what they have learned. In S. Schuman (Ed.), Creating a culture of collaboration: The International Association of Facilitators Handbook. California: Jossey-Bass.

Karafin, M. S., Tranel, D., \& Adolphs, R. (2004). Dominance attributions following damage to the ventromedial prefrontal cortex. Journal of Cognitive Neuroscience, 16, $1796-1804$

Katz, D., Maccoby, N., Gurin, G., \& Floor, L. (1951). Productivity, supervision, and morale among railroad workers. Michigan: University of Michigan Press.

King, A. J., Johnson, D. P., \& Van Vugt, M. (2009). The origins and evolution of leadership. Current Biology, 19, 11-16.

Kowner, R. (2001). Psychological perspective on human developmental stability and fluctuating asymmetry: Sources, applications and implications. British Journal of Psychology, 92, 447-469.

Leung, B., \& Forbes, M. R. (1996). Fluctuating asymmetry in relation to stress and fitness: Effects of trait type as revealed by meta analysis. Ecoscience, 3, 400-413.

Liden, R. C., \& Antonakis, J. (2009). Considering context in psychological leadership research. Human Relations, 62, 1587-1605.

Little, A. C., \& Jones, B. C. (2006). Attraction independent of detection suggests special mechanisms for symmetry preferences in human face perception. Proceedings of the Royal Society, 273, 3093-3099.

Littlepage, G. E., Robinson, W., \& Reddington, K. (1997). Effects of task experience and group experience on group performance, member ability, and recognition of expertise. Organizational Behavior and Human Decision Processes, 69, 133-147.

Lord, R. G., Brown, D. J., Harvey, J. L., \& Hall, R. J. (2001). Contextual constraints on prototype generation and their multilevel consequences for leadership perceptions. The Leadership Quarterly, 12, 311-338.

Lord, R. G., De Vader, C. L., \& Alliger, G. M. (1986). A meta-analysis of the relation between personality traits and leadership perceptions: an application of validity generalization procedures. Journal of Applied Psychology, 71, 402-410.

Mann, R. D. (1959). A review of the relationships between personality and performance in small groups. Psychonomic Bulletin, 56, $241-270$.

Mazur, A., Halpern, C., \& Udry, J. R. (1994). Dominant looking male teenagers copulate earlier. Ethology and Sociobiology, 15, 87-94.

Mazur, A., Mazur, J., \& Keating, C. (1984). Military rank attainment of a West Point class: Effects of the cadets physical features. American Journal of Sociology, 90, 125-150.

Mazur, A., \& Mueller, U. (1996). Facial dominance. In A. Somit, \& S. Peterson (Eds.), Research in biopolitics. London: JAI Press.

Mazur, A., \& Mueller, U. (1996). Channel modelling: From West Point cadet to general. Public Administration Review, 56, $191-198$.

Møller, A. P., \& Swaddle, J. P. (1997). Asymmetry, developmental stability and evolution. Oxford: Oxford University Press.

Mueller, U., \& Mazur, A. (1996). Facial dominance of West Point cadets as a predictor of later military rank. Social Forces, 74, 823-850.

Nemanich, L. A., \& Keller, R. T. (2007). Transformational leadership in an acquisition: A field study of employees. The Leadership Quarterly, $18,49-68$.

Nicholson, N. (1998). How hardwired is human behavior. Harvard Business Review, 76, 134-147.

Nicholson, N. (2005). Meeting the Maasai: Messages for management. Journal of Management Inquiry, 14, $255-267$.

Nicholson, N., \& White, R. (2006). Darwinism-A new paradigm for organizational behavior? Journal of Organizational Behavior, 27, 111-119.

Noor, F., \& Evans, D. C. (2003). The effect of facial symmetry on perceptions of personality and attractiveness. Journal of Research in Personality, 37, 339-347.

Oosterhof, N. N., \& Todorov, A. (2008). The functional basis of face evaluation. Proceedings of the National Academy of Sciences, $105,11087-11092$.

Palmer, B., Walls, M., Burgis, Z., \& Stough, C. (2001). Emotional intelligence and effective leadership. Leadership and Organizational Development Journal, 22, 5-10.

Pawar, B. S., \& Eastman, K. K. (1997). The nature of contextual influences on transformational leadership: A conceptual examination. Academy of Management Review, 22, 80-109.

Penton-Voak, I. S., Jones, B. C., Little, A. C., Baker, S., Tiddeman, B., Burt, D. M., et al. (2001). Symmetry, sexual dimorphism in facial proportions and male facial attractiveness. Proceedings of the Royal Society, 268, 1617-1625.

Penton-Voak, I. S., \& Perrett, D. I. (2000). Female preference for male faces changes cyclically - Further evidence. Evolution and Human Behavior, 21, 39-48.

Penton-Voak, I. S., \& Perrett, D. I. (2001). Male facial attractiveness: Perceived personality and shifting female preferences for male traits across the menstrual cycle. Advances in the Study of Behavior, 30, 219-259.

Penton-Voak, I. S., Perrett, D. I., Castles, D. L., Kobayashi, T., Burt, D. M., Murray, L. K., et al. (1999). Female preference for male faces changes cyclically. Nature, 399, $741-742$.

Povinelli, D. J., \& Preuss, T. M. (1995). Theory of mind: Evolutionary history of a cognitive specialization. Trends in Neurosciences, $18,418-424$.

Preston, S. D., \& de Waal, F. B. M. (2002). Empathy: Its ultimate and proximate bases. Behavioral and Brain Sciences, $25,1-71$.

Prokosch, M. D., Yeo, R. A., \& Miller, G. F. (2005). Intelligence test with higher g-loadings show higher correlation with body symmetry: evidence for a general fitness factor medicated by developmental stability. Intelligence, 33, 203-213.

Rhodes, G., Zebrowitz, L. A., Clark, A., Kalick, S. M., Hightower, A., \& McKay, R. (2001). Do facial averageness and symmetry signal health? Evolution and Human Behavior, 22, 31-46.

Rosener, J. B. (1990). Ways women lead. Harvard Business Review, 68, 119-125.

Senior, C. (2003). Beauty in the brain of the beholder. Neuron, 38, 525-528.

Senior, C., Lee, N., \& Butler, M. J. R. (2011). Organizational Cognitive Neuroscience. Organization Science, 22, 804-815.

Small, S. A., Shepard-Zeldin, R., \& Savin-Williams (1983). In search of personality traits: A multimethod analysis of naturally occurring prosocial and dominance behavior. Journal of Personality, 51, 1-16.

Sorcher, M., \& Brant, J. (2002). Are you picking the right leaders? Harvard Business Review, 80, 78-85.

Stogdill, R. M. (1974). Handbook of leadership: A survey of theory and research. New York: Free press.

Tinbergen, N. (1963). On the aims and methods in ethology. Zeitschrift fur Tierpsychology, 20, 410-433.

Turner, N., Barling, J., Epitropaki, O., Butcher, V., \& Milner, C. (2002). Transformational leadership and moral reasoning. Journal of Applied Psychology, 87, 304-311. 
Van Valen, L. (1962). A study of fluctuating asymmetry. Evolution, 16, 125-142.

Van Vugt, M., \& De Cremer, D. (1999). Leadership in social dilemmas: The effects of group identification on collective actions to provide public goods. Journal of Personality and Social Psychology, 76, 587-599.

Van Vugt, M., Hogan, R., \& Kaiser, R. B. (2008). Leadership, followership and evolution. American Psychologist, 63, 182-196.

Van Vugt, M., \& Schaller, M. (2008). Evolutionary approaches to group dynamics: An introduction. Group Dynamics, 12, 1-6.

Viswesvaran, C., Schmidt, F. L., \& Ones, D. S. (2005). Is there a general factor in ratings of job performance? A meta-analytic framework for disentangling substantive and error influences. Journal of Applied Psychology, 90, 108-131.

Waddington, C. H. (1957). The strategy of the genes. London: Allen and Unwin.

Warr, P. (1990). The measurement of well-being and other aspects of mental health. Journal of Occupational Psychology, 63, 193-210.

Weis, S. (2008). Theory and Measurement of Social Intelligence as a Cognitive Performance Construct. Unpublished doctoral dissertation, University of Magdeburg, Germany.

Wilson, E. O. (1978). What is sociobiology ? Society, 15, 10-14

Yammarino, F. J., \& Dubinsky, A. J. (1994). Transformational leadership theory: Using levels of analysis to boundary. Personnel Psychology, $47,787-811$.

Yeo, R. A., \& Gangestad, S. W. (1998). Developmental instability and phenotypic variation in neural organization. In N. Raz (Ed.), The other side of the error term: Aging and development as models in cognitive neuroscience (pp. 1-51). Amsterdam: Elsevier.

Zaatari, D., \& Trivers, R. (2007). Fluctuating asymmetry and behavior in the ultimatum game in Jamaica. Evolution and Human Behavior, $28,223-227$.

Zebrowitz, L. A., Hall, J. A., Murphy, N. A., \& Rhodes, G. (2002). Looking smart and looking good. Facial cues to intelligence and their origins. Personality and Social Psychology Bulletin, 28, 238-249. 